\title{
Design of a Vibration Monitoring System for the Hoisting Machine in Ship Locks
}

\author{
Panpan Zhang ${ }^{1,}$, Haibo $\mathrm{Li}^{2, \mathrm{~b}}$ \\ ${ }^{1}$ China Waterborne Transport Research Institute, Beijing 100088, China; \\ ${ }^{2}$ Key Laboratory of Logistics Equipment \& Control Engineering, Beijing 100088, China. \\ apeterpan9152@126.com, blihaibo@wti.ac.cn
}

Keywords: water transportation, ship lock, hoisting machine, horizontal gear reducer, vibration monitoring.

\begin{abstract}
Water transportation are becoming more and more important in the transportation area. The ship lock is one of the most significant facilities in the inland water transportation. In this paper, different kinds of hoisting machines for the ship lock gate were introduced. Characteristics of the connecting rod hoisting machine and the hydraulic cylinder hoisting machine were summarized. And for the connecting rod hoisting machine, a vibration monitoring system for the horizontal gear reducer and the vertical shafted cone \& cylinder gear reducer was designed to investigate the performance of the ship lock.
\end{abstract}

\section{Introduction}

As the inland water transportation develops, ship locks are playing more and more important role in this field. Heretofore, over 2000 ship locks have been built and put into use in China. And thousands of ship locks are working all around the world. The hoisting machine which is critical for the ship lock running directly provides power to the lock gate. Taking the Three Gorges lock for example, the capacity of the lock was over 100 million tons in the year of 2014[1]. This hoisting machine is responsible for the opening and closing of the ship lock. The operation state of the hoisting machine greatly affects running conditions of the ship lock. With the development of the technology of testing and diagnosis, the vibration monitoring and fault diagnosis methods have been widely applied in the various industries such as the chemistry factory, aerospace and wind generation fields [2-4]. However, the vibration monitoring and fault diagnosis technology applied in the ship lock are still not popular. In this paper, different kinds of hoisting machines for the ship lock gate were introduced. Meanwhile, characteristics of hoisting machines were summarized. And for the connecting rod hoisting machine, a vibration monitoring system was designed to investigate the operation state.

\section{Hoisting machines for the ship lock}

The hoisting machine is the power element for the gates of ship locks. With the development of mechanical technology, different types of hoisting machines were designed and put into use. So far, there are several kinds of hoisting machine applied in the ship lock such as the gate drum set hoist (shown in Fig. 1), the screw type hoist (shown in Fig. 2), the connecting rod type hoisting machine, the hydraulic cylinder type hoisting machine[5] and so on.

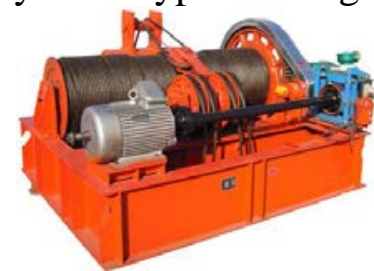

Fig. 1 The drum set hoisting machine

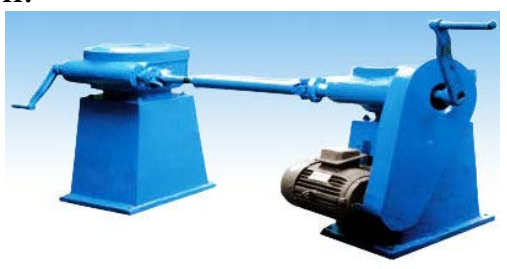

Fig. 2 The screw type hoisting machine 
In this paper, the connecting rods type and hydraulic cylinder type ship lock gate hoist which were used in Gezhouba ship lock and the Three Gorges ship lock were introduced and discussed.

The link rods type hoisting machine shown in Fig. 3 are composed of a motor, a brake, a horizontal gear reducer, gear couplings, a vertical shafted cone \& cylinder gear reducer, a sector gear, a push-pull rod and the gate. The horizontal gear reducer and vertical cone \& cylinder gear reducer directly transfer power to the gate. So the performance of gear reducers greatly affect the stability of the hoisting machine. In particular, when serious abrasion in the gear box happens, the ship lock gate will vibrate and maybe cause accidents. So far, the vibration monitoring technology has not been widely used for the ship lock which causes the maintenance delay of hoisting machines.

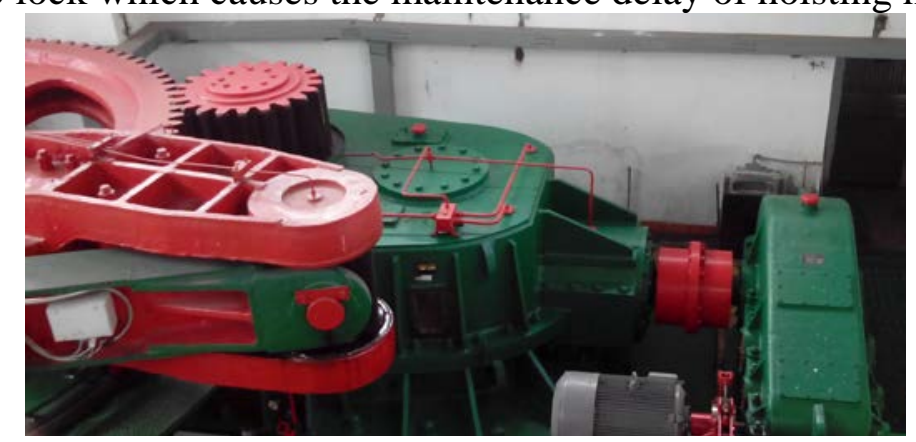

Fig. 3 Structure of the connecting rod type hoisting machine

The hydraulic cylinder hoisting machine for the ship lock shown in Fig. 4 is composed of a cylinder with a large diameter, a hydraulic station, motors, valves and pipes. The hydraulic cylinder was directly connected the ship lock gate. The hydraulic cylinder could provide stable power to the gate so that this kind of hoisting machines are widely applied in the ship lock.

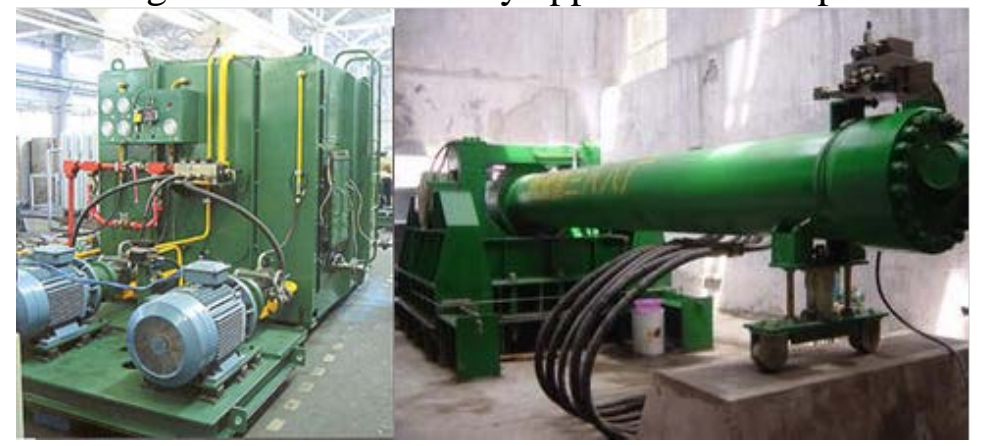

Fig. 4 Composition of the hydraulic cylinder hoisting machine

\section{Design of the vibration monitoring system}

For the connecting rod type hoisting shown in Fig. 1, the horizontal gear reducer and the vertical cone \& cylinder gear reducer are really important elements and have great influence on the performance of the ship lock.

The horizontal gear reducer includes three-stage gear transmission. In order to test the vibration of the reducers, acceleration transducers are chosen to investigate the performance shown in Fig. 5. Two acceleration transducers are placed on the motor. And there are two acceleration transducers fixed on each gear shaft. And three acceleration transducers are placed on three ends of shafts. Because the vertical cone \& cylinder gear reducer is placed after the horizontal gear reducer, the vibration frequency is much lower than that of the horizontal gear reducer. In that condition, low frequency acceleration transducers were chosen. 


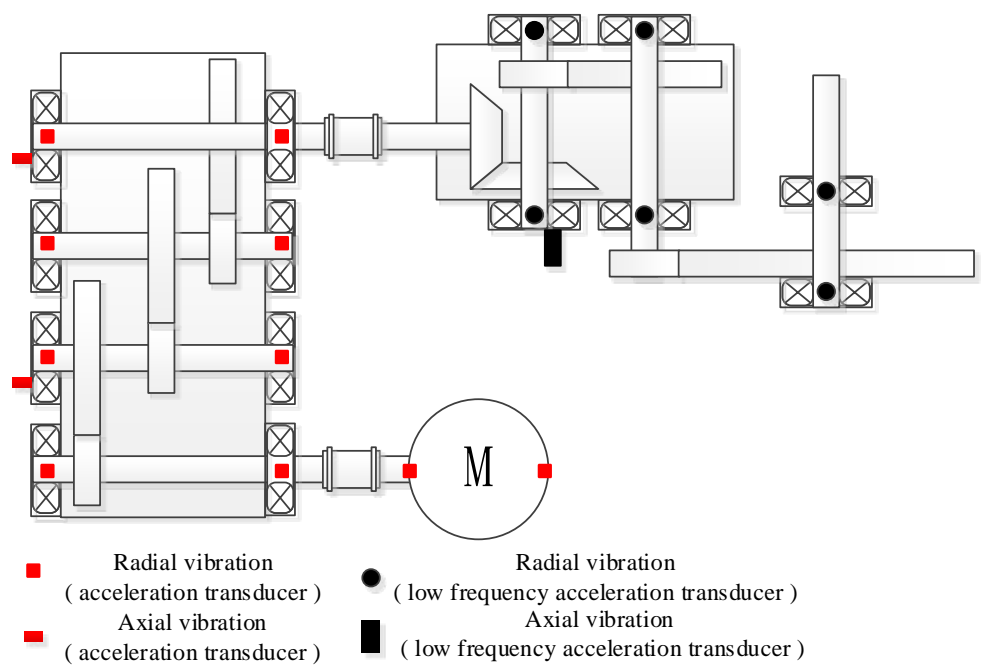

Fig. 5 The arrangement of the acceleration transducers

Each acceleration transducer could provide acceleration signals and velocity signals. The acceleration signal are sensitive to the bearing and gear performance. And the velocity signal are sensitive to the rotating shaft. Acceleration signals and velocity signals can be used for the fault diagnosis of the hoisting machine.

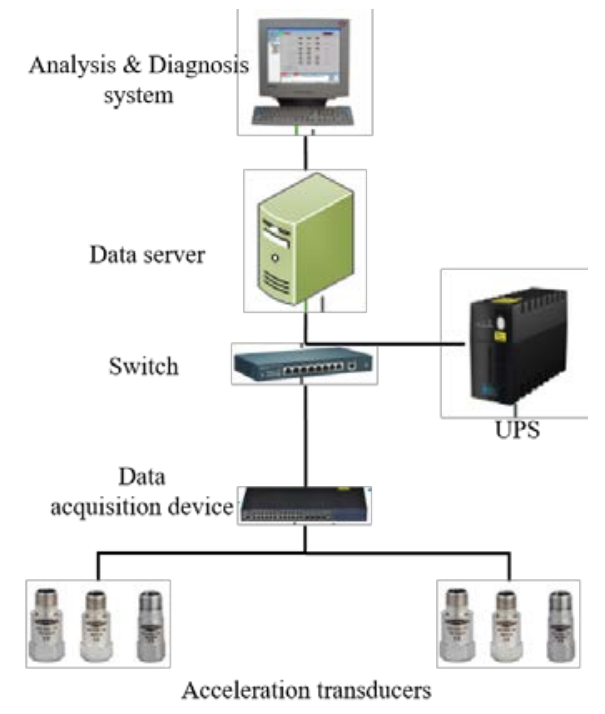

Fig. 6 Structure of the vibration monitoring \& diagnosis system

The vibration system shown in Fig. 6 includes acceleration transducers, a data acquisition device with 24 inputs, a data switch, an uninterrupted power supply (UPS), a data server and an analysis \& diagnose system. With the help of the vibration monitoring system, acceleration and velocity signals are firstly obtained via transducers and the data acquisition device. Through a data switch and a data server, signals could be analyzed. If abnormal signal is detected, the analysis is carried out through the software. According to the software setting, a preliminary diagnose conclusion could be drawn and can be used for further investigation and maintenance. The system will improve the management ability of the ship lock.

\section{Conclusions}

In this paper, several hoisting machine used for the ship lock gate were introduced. Characteristics of the connecting rod type hoisting machine and the hydraulic cyclinder type hoisting machine were mainly discussed. For the the connecting rod type hoisting machine, the vibration monitoring technology was used for monitoring the running status of the horizontal gear reducer and the vertical cone \& cylinder gear reducer. Meanwhile the vibration monitoring and diagnosis system was 
designed. In future, the system will be applied in the ship lock and the performance of the system can be investigated and improved.

\section{References}

[1]. Liao Peng, Review on research of lock capacity at inland waterway locks, Hydro-science and Engineering. 2009, 3, p.34-38.

[2]. Rubini R, Meneghetti U. Application of the Envelope and Wavelet Transform Analyses for the Diagnosis if Incipient Faults in Ball Bearing. Mechanical Systems and Signal Processing. 2001, 15(2),p.287 302.

[3]. Joselin Herbert GM, Iniyan S, Rajapandian S.et al. A review of wind energy technologies [J]. Renew Sustain Energy Review. 2007, 11(6), p.1117-1145.

[4]. Mechefske C K. Objective Machinery Fault Diagnosis Using Fuzzy Logic. Mechanical Systems and Signal Processing, 1998, 12(6),p.855 862

[5]. Liu Zhenhuai, The design of hydraulics system for shiplock hoist of Subei canal, Chinese Hydraulics \& Pneumatics. 2008, 12, p. 32-34. 